\title{
Research on the Bilingual Teaching in the University
}

\author{
Xuemei Bai \\ School of Electronic and Information Engineering \\ Changchun University of Science and Technology \\ Changchun, China \\ xmbai@cust.edu.cn
}

\section{Jinghui Su}

School of Electronic and Information Engineering Changchun University of Science and Technology

Changchun, China

171592615@qq.com

\author{
Yang $\mathrm{Lu}^{*}$ \\ School of Electronic and Information Engineering \\ Changchun University of Science and Technology \\ Changchun, China \\ 457625762@qq.com \\ * Corresponding Author
}

\begin{abstract}
The effective implementation of bilingual teaching can help students acquire forefront academic expertise, master a foreign terminology in some areas of expertise, improve their foreign language skills, lay a good foundation for their participation in international exchanges in the future and develop the international compound talents. The paper analyzed the bilingual teaching from the definition, the cultivation of teachers, the requirements for students and the teaching materials types and showed the achievements of the bilingual teaching. The paper also pointed out the current problems in the bilingual teaching and the solutions.
\end{abstract}

Keywords- bilingual teaching; cultivation of teachers; students; teaching material; university

\section{INTRODUCTION}

With the world economic integration, exchanges and development of international cultural, bilingual communication becomes an increasingly common phenomenon and bilingual teaching has also attracted wide attention of scholars both at home and abroad (Xiaoxu Wei, 2014). Bilingual teaching is meant to cultivate the students' basis thinking ability, smart structure, and culture quality with the help of language media. In the open language environment, it can maximally excavate the potential of students. Bilingual teaching is an inevitable requirement for economic and knowledge globalization and an inevitable requirement for higher education to implement global technological development and technical exchanges And bilingual teaching is not only conducive to cultivate local talents with the international competitiveness, but also to attract more international students, and therefore, it can effectively improve the international competitiveness of domestic education.

\section{DEFINITION OF BILINGUAL TEACHING}

There are many types of definitions for the bilingual teaching. Generally speaking, bilingual teaching refers that a kind of foreign language is a means of teaching and learning process is through bilingual teaching expertise in non-foreign language courses to deepen the education cognition of professional course learning students and make students have the ability of international exchange and cooperation to achieve the improvement of comprehensive quality (Danhuai Lu, 2001). Bilingual teaching is different from a simple language for the purpose of education itself. "Language teaching" refers to learning a language course through the school education system, and the purpose of these courses is to help and train students to master a foreign language knowledge and language skills. The "education language" is being used as a medium of language to teach certain specific language knowledge. Bilingual teaching in universities is breaking the original foreign language education mode and specialized course teaching mode so that the students can master professional terminology and language expression features effectively (Duojiao Tan, 2010). Effective development of bilingual teaching is good for students to obtain frontier subject professional knowledge, master professional language terminology, improve the students' foreign language level and lay a good foundation for the participation in international communication in the future.

Bilingual teaching means using two languages as teaching media to help students apply the two languages in learning professional knowledge. One kind of the two languages is usually the student's native language and the other is a foreign language which students need to master. The goal of bilingual teaching is to train students with the ability to use both languages. But the means of achieving this goal is not through the language as a subject. Accurately, bilingual education means that two languages are the medium of teaching language, which makes students achieve the ultimate goal of master two languages through teaching language (Danhuai Lu, 2001). The traditional foreign language education focused on grammar learning, but ignored the students' language application ability. Therefore, it was not suitable for the requirements of the new times. Bilingual teaching in universities is breaking the original mode of foreign language education and specialized course teaching mode, so the students can 
not only effectively master discipline professional terms but also have good language expression ability. To prompt the development of language ability in teaching language is the essence of the bilingual teaching.

\section{CULTIVATION OF TEACHERS}

Bilingual teachers as the main resource and the most direct perpetrators in bilingual teaching are the key intermediary to achieve the goal of bilingual teaching. American bilingual education began in 1568, was one of the oldest bilingual education implementation in the world. United States reached a consensus on such a long-term process of bilingual education. The quality of the bilingual education depends on the quality of bilingual teachers. Qualified bilingual teachers are nonverbal outstanding teachers who have a high level of knowledge and ability. Qualified bilingual teachers should not only have a high level of professional knowledge but also strong knowledge of foreign language. They should be able to use a foreign language to express what they want to say skillfully. United States attaches great importance to bilingual teacher in-service training and formed a distinctive bilingual teacher training system and pattern. Since the late 1980 s, most states have tried to expand bilingual teachers to service training programs and to improve the level of bilingual teachers' work and the distribution of permanent bilingual teachers' qualification certificate and other incentives to encourage the bilingual teachers' in-service training and improvement. Canada's bilingual education has a history of 40 years, as a widely implemented high quality bilingual education country, their demand for bilingual teachers are also very high. For example, the schools require bilingual teachers candidates clearly must be a high level of bilingual bicultural person with a high level of education and a high teaching level and they must be excellent subject teachers. Finland bilingual teachers' job application and bilingual teachers' qualification examination and approval mainly accord to the comprehensive ability to use bilingual and bilingual teaching level (Liying Wang, 2005).

The current situation in China is that bilingual teachers are mostly school faculties of professional teachers and in general they are proficient in professional teaching but lack of the necessary foreign language teaching theory and fundamental language skills. So cultivating high quality of bilingual teachers is the key to guarantee the high quality bilingual teaching.

Universities can set up a special training for bilingual teacher training funds to ensure the quality of bilingual teachers. Training plan should include a variety of language knowledge, cultural diversity knowledge and other learning and research about bilingual teaching methods. In the meantime, the native teachers should associate with foreign teachers to explore the bilingual education skills to make progress together. Colleges and universities should pay more attention to the on-the-job training and enhancements of bilingual teachers' knowledge and ability, which can cultivate high quality bilingual teachers and effectively ensure the high quality and rapid development of bilingual education (Liying Wang, 2005). In addition, bilingual teachers should have a certain teaching research level to make some introspection and improvement on their teachings.

\section{REQUIREMENTS FOR STUDENTS}

Bilingual teaching is to improve students' foreign language level and to enable students to master professional knowledge. Students of bilingual courses need more efforts and work harder in their study than that of students without bilingual courses. Especially in the language, the level of language will directly influence on the effect of learning course. There are a lot of specialized vocabularies and terminology in the various professional disciplines. Some ordinary language terms commonly used in the professional field have other special interpretations and even the same words in different professions have different meanings. Without special study and training, students often are not familiar with the professional foreign language vocabularies and not familiar with the grammar and discourse features, which will make students read professional literature slowly and therefore, their professional foreign language communication ability is poor. There is no doubt that they cannot meet the requirements for bilingual teaching (Dahu Zheng \& Huihua Dai, 2013). To improve their language skills is not easy. The improvement of language ability is not happening overnight, students need to learn in everyday life and gradually improve the ability in foreign language environment. According the Threshold Theory ( or the Threshold Hypothesis) from Cummins, when the students master the second language and it's enough to meet the teaching requirements, such as, understanding the course content and the curriculum content to form concepts, then the bilingual teaching will have a positive effect on students' cognitive development (Cummins 1984). Before bilingual teaching in colleges and universities, students' foreign language level is one of the key factors for success of learning (Jianxia Han \& Mingyu Li, 2007). The students who have resistance on bilingual teaching usually may have bad English foundation or they cannot keep pace with the curriculum progress because they didn't get the timely help from the teachers.

It's visible that the teaching effects will not be ideal if the teachers don't consider the student's English level and don't care about the students' acceptance ability. It will make it difficult for teachers to freely use a foreign language in teaching if the employed teaching method and means are much higher than the students' cognitive level. It's no doubt that the enthusiasm is destructive and it will be counterproductive (Duojiao Tan, 2010).

Native students should actively communicate with international students. They can make a better understanding about foreign humanities and exercise their own foreign language listening and speaking skills through the communication. Under the conditions of making choices, students should choose more foreign language electives. Because these kinds of courses are not very strict with students and students are relatively easy to learn. Language is not only an instrument of human thought, but also an important factor of the human mind. After the learning of multiple languages will improve the students' language thinking ability and it will not just confine to the use of two languages. The fusion of different kinds of languages and different culture can enlarge students' horizons and have an active influence on the bilingual teaching and learning. 


\section{ANALYSIS OF TEACHING MATERIALS TYPE}

Teaching materials are the carrier of the teaching content and a bridge between teachers and students. Teaching materials are the important factors that affect the teaching effect. Therefore, the bilingual teaching materials' selection and reasonable use are particularly important. It's considered that a bilingual teacher is excellent if the teacher can pay much attention to the excellent teaching materials for cultivating high-quality talents (Minrui Zhang, 2007). There are four types of bilingual teaching materials in general as shown in the following.

\section{A. Foreign original teaching materials}

For a university, the core problem of the internationalization is that must to cultivate competitive talents in ideology, knowledge and skills who have a deeper knowledge of domestic and international. Therefore, in order to in line with international standards as soon as possible and foster the students' ability of international communication, it is necessary to introduce original foreign materials directly.

Original contents reflect the prospective foreign language teaching theory and help students understand the theoretical knowledge and the latest cutting-edge professional practice development. What's more, selecting the original foreign language materials for students can create a comprehensive foreign language environment, including the use of specialized vocabulary accurate and precise expression of professional content. This really makes in-class teaching can keep pace with the world's mainstream technology and professional ideas as the world standards from the form and content to work with (Duojiao Tan, 2010). Directly importing high quality original teaching materials in bilingual teaching not only can save time and effort and avoid bias or arbitrariness when translating materials on the subject knowledge, but also can optimize the teaching content, update educational concepts and adjust teachers' teaching methods. In the long run, it's the best choice to improve teaching effectiveness and improve the quality of personnel training. However, it obviously makes a high requests for both teachers and students in the foreign languages.

\section{B. Handouts from teachers}

Many teachers think that the difference between existing original and photocopy versions is large and no one is able to meet the teaching requirements of their own university. They can only copy the appropriate parts of content from a variety of original or photocopied version and then distribute them to their students. If they can't find the content they need, they must write them in foreign language by themselves. In this case, teachers just send students what they need to teach and students finally get all the content is scattered sheet properties of materials. Such materials have strong targeted and flexibility and be more economical and practical. However, it is difficult to ensure the quality of such materials and the students are very inconvenient to use and save.

\section{Teaching materials from the international university cooperation}

In theory, material co-authored by the national experts is the best way. However, the requirement of the author is very high. The experts must be experts on this subject direction and have a high level of foreign language. They have also enough time, energy and enthusiasm into the active materials preparation. At present, these conditions are met very few teachers, so the optimal and most promising way is actually the most difficult.

\section{Teaching materials adaptation from original materials}

Currently, the approach most universities adopted is adapting the teaching materials from original materials abroad for specialized courses in accordance with the requirements of their own schools and they continue to modify and improve in practice. Teachers can take effective transitional measures for the introduction, analysis, integration, modification and a series of localization transformation for the outstanding foreign original teaching materials to truly meet the needs of their bilingual teaching in colleges and universities. This method not only can keep their own teaching material logic and systematic characteristics to build the bilingual teaching architecture, but also learn from original materials focusing on practicality and advantages of student research training capacity and the spirit of exploration. By this way, the quality of bilingual teaching and the original language features will be ensured. This is the important way to solve the present bilingual teaching materials selection problem (Yueyun Dai et al. 2009).

\section{ACHIEVEMENTS AND PROBLEMS}

The bilingual teaching is adopted all over world and it has got a lot of achievements.

The world-famous bilingual teaching experiment was started in 1965, in Quebec, Canada Montreal Lambert's primary school, and got the popularization in Canada. It has caused the great attentions from educators, psychologists and linguists all over the world. It is considered to be the most successful teaching mode in the bilingual teaching. From 1965 to the present, not just in Canada, there have been nearly millions of primary and middle school students accept this mode and achieved actual effects. French Immersion Programs is Canada's most in-depth research on educational history, the most detailed and the most extensive project of a bilingual education. In the world, many countries have carried out the immersion bilingual teaching experiment and it has trained a large number of bilingual talents who have solid language foundation and professional ability. In addition, foreign language or minority language immersion bilingual education experiment were implemented in Finland, USA, South Africa and other regions and also received good results.

But in order to provide bilingual courses, the government has to spend taxpayers' money to train teachers in order to meet the needs of such courses. Some people think that the students' opportunity to use a foreign language out of school is little because they live in a native language-based environment and therefore, it is difficult to improve foreign language. There are also some people believe that teachers' foreign language level is limited and this makes the results of foreign language teaching unsatisfactory. Although there are foreign teachers in colleges and universities, but many of them do not 
understand the professional knowledge. If they teach professional class instead, it would be counterproductive. And no matter how high the foreign language level of native teachers, it is difficult to think and teach totally in a foreign mode. The realistic contradiction will naturally affect the effectiveness of bilingual education.

\section{EXPECTATION}

As for a country or a region, the more schools adopt bilingual teaching, the more bilingual talents will exist. Accordingly, it can accept the international advanced science and technology in a faster speed. With the progress of education, the education concept is upgraded and people are gradually realizing that language is not only a communication tool, but also a tool of thinking, which is learned from all over the world and methods and habits in the same way. It can exchange the students' world view and outlook on life and have a profound impact on the quality of students. In summary, the bilingual education is an integral part of quality education based on the above understanding whether by subjective or by objective.

\section{REFERENCES}

[1] G. Eason, B. Noble, and I. N. Sneddon, "On certain integrals of Lipschitz-Hankel type involving products of Bessel functions," Phil. Trans. Roy. Soc. London, vol. A247, pp. 529-551, April 1955. (references)

[2] J. Clerk Maxwell, A Treatise on Electricity and Magnetism, 3rd ed., vol. 2. Oxford: Clarendon, 1892, pp.68-73.

[3] I. S. Jacobs and C. P. Bean, "Fine particles, thin films and exchange anisotropy," in Magnetism, vol. III, G. T. Rado and H. Suhl, Eds. New York: Academic, 1963, pp. 271-350.

[4] K. Elissa, "Title of paper if known," unpublished.

[5] R. Nicole, "Title of paper with only first word capitalized," J. Name Stand. Abbrev., in press.

[6] Y. Yorozu, M. Hirano, K. Oka, and Y. Tagawa, "Electron spectroscopy studies on magneto-optical media and plastic substrate interface," IEEE Transl. J. Magn. Japan, vol. 2, pp. 740741, August 1987 [Digests 9th Annual Conf. Magnetics Japan, p. 301, 1982].

[7] M. Young, The Technical Writer's Handbook. Mill Valley, CA: University Science, 1989.

[8] Electronic Publication: Digital Object Identifiers (DOIs):

[9] D. Kornack and P. Rakic, "Cell Proliferation without Neurogenesis in Adult Primate Neocortex," Science, vol. 294, Dec. 2001, pp. 2127-2130, doi:10.1126/science. 1065467.

[10] H. Goto, Y. Hasegawa, and M. Tanaka, "Efficient Scheduling Focusing on the Duality of MPL Representatives," Proc. IEEE Symp. Computational Intelligence in Scheduling (SCIS 07), IEEE Press, Dec. 2007, pp. 57-64, doi:10.1109/SCIS.2007.357670. 